\title{
Profitabilitas (ROA) Dipengaruhi Oleh Manajemen Kas
}

\author{
R. Apriyanto ${ }^{1}$ \& A. Surachim \\ Universitas Pendidikan Indonesia \\ riko.apriyanto@student.upi.edu
}

\begin{abstract}
The Purpose of this research is to find out the description of Profitability (ROA) that is influenced by cash management. This type of research used are descriptive, verifikatif. The sampling technique used documentation study. Data analysis technique used is simple linear regresion with computer software SPSS 21.0. Based on the results of the research that cash management influence on profitability. The differences in this study located on an object research, time research, literature that used, the theory that is used and the results of the study
\end{abstract}

\footnotetext{
ABSTRAK

Tujuan penelitian ini adalah untuk mengetahui gambaran Profitabilitas (ROA) yang dipengaruhi oleh Manajemen Kas. Jenis penelitian yang digunakan adalah deskriptif, verifikatif dan teknik pengumpulan data menggunakan studi dokumentasi. Teknik analisis data yang digunakan adalah regresi linear sederhana dengan alat bantu software komputer SPSS 21.0. Berdasarkan hasil penelitian dapat diketahui bahwa manajemen kas berpengaruh terhadap profitabilitas. Perbedaan dalam penelitian ini terletak pada objek penelitian, waktu penelitian, literatur yang digunakan, teori yang digunakan dan hasil penelitian.
}

\author{
ARTICLE INFO: \\ Article history: \\ Received 6 Februaryl 2017 \\ Revised 6 February 2017 \\ Accepted 8 February 2017 \\ Available online 20 May \\ 2017
}

Keywords:

Cash Management,

Profitability,

Return On Assets (ROA)..

\author{
Kata Kunci: \\ Profitabilitas, \\ Manajemen Kas, \\ Return Of Assets (ROA).
}

\section{PENDAHULUAN}

Profitabilitas merupakan rasio menilai kemampuan perusahaan dalam mencari keuntungan. Rasio ini juga memberikan ukuran tingkat efektivitas manajemen suatu perusahaan, dalam hal ini ditunjukkan oleh laba yang dihasilkan dari penjualan dan pendapatan investasi, Kasmir (2011:196)

Menurut Jopie Yusuf (2008:66-72) "Faktor-faktor rasio pengukur profitabilitas yaitu Gross Profit Margin, Net Profit Margin, Return On Assets (ROA) dan Return On Equity (ROE). Brigham dan Houston (2006:89) menyatakan "Rasio profitabilitas menunjukkan pengaruh gabungan dari likuiditas, manajemen aktiva dan utang terhadap hasil operasi. Selain itu, margin laba bersih, perputaran total aktiva, pertumbuhan perusahaan serta ukuran pun mampu mempengaruhi profitabilitas". Mardiyanto (2009:196) "Return On Assets (ROA), merupakan rasio yang digunakan untuk mengukur kemampuan perusahaan dalam menghasilkan laba yang berasal dari aktivitas investasi". Irham (2012:98) juga menyatakan "ROA digunakan untuk melihat sejauh mana 
investasi yang telah ditanamkan mampu memberikan pengembalian keuntungan sesuai dengan yang diharapkan berdasarkan aset yang dimiliki”. Profitabilitas juga memiliki arti penting dalam kelangsungan hidup perusahaan dalam jangka panjang. Dengan demikian perusahaan akan selalu berusaha meningkatkan profitabilitasnya. Karena semakin tinggi tingkat profitabilitas maka kelangsungan hidup perusahaan akan semakin terjamin. Seperti yang dikemukakan oleh Giulio Bottazzi, Angelo Secchi dan Federico Tamagni (2008) “A comparative analysis of two crucial dimensions of firms performance: profitability and productivity, and find independently from the particular sector of activity and from financial conditions, there seems to be weak market pressure and little behavioral inclination for the more efficient and more profitable firms to grow faster". Menurut Syamsuddin (2009:59) "Perhatian ditekankan pada profitabilitas, karena untuk dapat melangsungkan hidupnya, suatu perusahaan haruslah berada dalam keadaan menguntungkan/profitable”. Profitabilitas perusahaan yang tinggi dapat diperoleh apabila aktiva yang di dalamnya terdapat unsur kas dikelola dengan baik yang mana disebut dengan manajemen kas. Seperti yang dikutip oleh Monika Bolek dan Wojciech Wilinski (2012:41) "Profitability ratios are the relation of income net to total assets involved in company activities. They show what amount of financial result is generated by a cash unit of the assets". Pendapat tersebut didukung oleh Fields (2011:143), "The profitability of any business is certainly affected by the amount of assets that are dedicated to that business. There assets include cash, accountreceivable, inventory and fixed assets".

Penelitian terdahulu, Yovica Kukuh Rian Aditya (2016) "Analisis Pengaruh Manajemen Kas Dan Rasio Keuangan Daerah
Terhadap Keputusan Investasi Pemerintah Daerah (Studi Kasus Pada Pemerintah Kabupaten Atau Kota Di Jawa Tengah Tahun 2011-2013)" mendapatkan kesimpulan bahwa Manajemen Kas Earning Power Of Total Investment, Rate Of Return Investment Tidak Berpengaruh Signifikan Terhadap Keputusan Investasi, Sedangkan Variabel Debt To Equity Ratio Dan Debt To Total Asset Ratio Berpengaruh Signifikan Terjadap Keputusan Investasi.Berarti manajemen kas sebagian besar mempengaruhi profitabilitas.

Tujuan penelitian ini adalah: (1) Untuk memperoleh temuan mengenai gambaran manajemen kas pada PT. Kalbe Farma, Tbk periode 2006-2015. (2) Untuk memperoleh temuan mengenai gambaran profitabilitas (ROA) pada PT. Kalbe Farma, Tbk periode 2006-2015. (3) Untuk memperoleh temuan mengenai gambaran pengaruh manajemen kas terhadap profitabilitas (ROA) pada PT. Kalbe Farma, Tbk periode 2006-2015.

\section{KAJIAN PUSTAKA}

Miko Wiliam (2010: 67) mendefinisikan manajemen kas "sebagai strategi dan proses untuk mengelola secara efektif dan efisien arus kas jangka pendek dan saldo-saldo kas yang ada dalam perusahaan. Perusahaan membutuhkan manajemen kas yang baik. Bobitan dan Mioc (2011: 302) menekankan pentingnya manajemen kas dimana manajemen kas mencakup semua pendapatan dan pembayaran yang dilakukan dalam jangka waktu tertentu, menyoroti inkonsistensi potensial yang dapat muncul untuk periode tersebut. Dengan manajemen kas terhadap perputaran kas perusahaan akan mampu meminimalisir penyelewengan kas sehingga secara langsung mempengaruhi profitabilitas perusahaan".

Selanjutnya, hasil studi yang dilakukan oleh Kakuru (2005) menyatakan bahwa 
"indicated that all businesses should aim at a collecting cash receipts and making payments efficiently to maintain a net balance of a surplus. If these receipts and payments collections are synchronised, a business will encounter this surplus net balance which is regarded as a business profit". Pendapat tersebut menunjukkan bahwa semua perusahaan harus bertujuan pada mengumpulkan penerimaan kas dan melakukan pembayaran secara efisien untuk menjaga keseimbangan bersih surplus. Jika penerimaan dan pembayaran disinkronisasi, perusahaan akan menghadapi neto dan kelebihan ini yang dianggap sebagai keuntungan bisnis.

\section{Konsep Manajemen Kas}

Manajemen kas menurut Rahmadi et al. (2006: 45) adalah "Pengelolaan atas sumber daya kas suatu organisasi/perusahaan. manajemen kas memberikan kepada manajemen alat untuk berfungsinya suatu organisasi dengan menggunakan kas atau sumber daya likuid yang dimilikinya dengan cara yang tepat.

Miko Wiliam (2010: mendefinisikan manajemen kas "sebagai strategi dan proses untuk mengelola secara efektif dan efisien arus kas jangka pendek dan saldo-saldo kas yang ada dalam perusahaan. Manajemen Kas (Cash Management) merupakan suatu kumpulan kegiatan perencanaan, perkiraan, pengumpulan pengeluaran dan investasi kas dari suatu perusahaan agar dapat beroperasi dengan lancar. Tanpa manajemen kas yang baik sebuah perusahaan bisa mengalami kebangkrutan karena kekurangan kas, walaupun ia menghasilkan profit. Karena situasi bisnis banyak memiliki ketidakpastian membutuhkan pengelolaan kas yang baik, Perencanaan kas yang baik akan dapat mengidentifikasi potensi krisis kas sebelum itu terjadi.

\section{Konsep Profitabilitas}

Profitabilitas merupakan rasio menilai kemampuan perusahaan dalam mencari keuntungan. Rasio ini juga memberikan ukuran tingkat efektivitas manajemen suatu perusahaan, dalam hal ini ditunjukkan oleh laba yang dihasilkan dari penjualan dan pendapatan investasi, Kasmir (2011:196)

Menurut Jopie Yusuf (2008:66-72) "Faktor-faktor rasio pengukur profitabilitas yaitu Gross Profit Margin, Net Profit Margin, Return On Assets (ROA) dan Return On Equity (ROE). Dan Syamsuddin (2009:61-66) mengemukakan bahwa untuk menghitung profitabilitas dapat digunakan rasio Gross Profit Margin (Margin Laba Kotor), Net Profit Margin (Margin Laba Bersih), Return On EquityRatio (ROE) dan Return On Assets (ROA) Serta Earning per share (EPS).

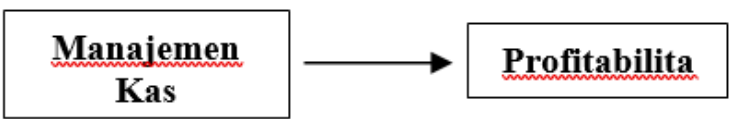

\section{Gambar 1 : Paradigma Penelitian}

\section{METODEPENELITIAN}

Penelitian ini dilakukan untuk mengetahui pengaruh manajemen kas terhadap profitabilitas (ROA). Variabel $\mathrm{X}$ adalah manajemen kas. Sementara variabel Y adalah profitabilitas dengan menggunakan rasio Return On Assets. Sampel pada penelitian ini yaitu laporan keuangan konsolidasian PT. Kalbe Farma, Tbk tahun 2006 sampai dengan 2015. Penelitian ini dilakukan pada kurun waktu sepuluh tahun. Teknik pengumpulan data yang digunakan pada penelitian ini adalah studi dokumentasi. Sedangkan teknik analisis data yang dilakukan adalah analisis deskriptif dan verifikatif. Analisis data verifikatif menggunakan regresi linear sederhana 
dengan bantuan software SPSS 21.0 for windows.

\section{HASIL DAN PEMBAHASAN}

Berdasarkan hasil pengujian deskriptif penelitian dilakukan dalam kurun waktu (N) 10 tahun dan nilai tertinggi dari variabel manajemen kas adalah 2.291 Triliun, nilai terendah 725 Miliar sedangkan dari variabel profitabilitas nilai tertinggi adalah $18,41 \%$ dan nilai terendah $10,66 \%$.

Hasil analisis data verifikatif diketahui nilai signifikansi (Sig.) sebesar 0,003 sedangkan probabilitas 0,05 dan berdasarkan perbandingan nilai $\mathrm{T}$ diketahui Thitung sebesar 4,133 sedangkan Ttabel yang diperoleh dari distribusi nilai $\mathrm{T}$ dengan taraf kesalahan $(\alpha)$ $0,05 / 2=0,025$ dan angka df nya $=\mathrm{N}-2=10$ $-2=8$, maka didapat nilai Ttabel sebesar 2,306. Karena nilai Thitung 4,133 > Ttabel 2,306 dan Sig. 0,003 < 0,05 sehingga dapat dinyatakan bahwa Ho ditolak dan Ha diterima, yang berarti bahwa ada pengaruh manajemen kas (X) terhadap Profitabilitas (X).

Adapun nilai R Square sebesar 0,681. Nilai ini mengandung arti bahwa pengaruh manajemen kas $(\mathrm{X})$ terhadap profitabilitas $(\mathrm{Y})$ adalah sebesar $68,1 \%$.

\section{KESIMPULAN DAN SARAN}

1. Manajemen kas sangat fluktuatif, adapun saldo terendah dan tertinggi secara berturut-turut terjadi pada tahun 2006 dan 2013 yaitu 725 Miliar dan 2,291 triliun.

2. Profitabilitas (ROA) mengalami peningkatan dari tahun 2006-2008 dan terjadi penurunan di tahun 2009 serta 2010 kemudian relatif meningkat dari tahun 2011-2014 dan menurun di tahun 2015.

3. Dari hasil pengujian dapat disimpulkan bahwa variabel bebas (X) yaitu manajemen kas mempunyai pengaruh terhadap variabel terikat (Y) yaitu profitabilitas (ROA) sebesar 68,1\%.

Berdasarkan hasil penelitian, maka penyusun menyarankan agar saldo kas disesuaikan dengan kebutuhan dalam setiap periode keuangan karena manajemen kas berpengaruh negatif terhadap profitabilitas sehingga apabila saldo kas berlebih maka akan mengurangi profitabilitas perusahaan, begitupun sebaliknya apabila kekurangan kas perusahaan tidak akan bisa membayar kebutuhan-kebutuhan jangka pende

\section{DAFTAR PUSTAKA.}

Akinyomi, O. J. 2014. Effect of Cash Management on Profitability of Nigerian Manufacturing Firms. International Journal of Marketing And Technology, 4(1):129-140.

Aliet, N. Cash Management and Profitability of Corporate Firms. A Case Study: MTN Uganda Ltd. Batchelor's DegreeBusiness Administration. of Bishop Stuart University. 2012.

Amoako, K. O., Marfo, E. O., Gyau, K. E. And Asamoah. F. O. 2013. "Cash Budgeting Imperative Element of Effective Financial Management". Canadian Social Science. 9 (5): 188-191.

Ambarwati, Sri Dwi Ari. (2010). Manajemen Keuangan Lanjut.Yogyakarta: Graha Ilmu..

Baridwan, Zaki, 2008, Intermediate Accounting, Cetakan Kedua, BPFE, Yogyakarta. 
Bastian Indra. 2002. Sistem Akuntansi Sektor Publik.Buku 1 Jakarta: Salemba Empat

Bobitan, N. And Mioc, A. D. 2011. Using Information on The Cash Flow Situation in Substantiating Entities' Decisions. Agricultural Management (Online), 13 (3): 299-306. Available At: Http://Search. Ebscohost.Com Login.Aspx? Direct $=$ True $\& D b=$ Bth\&AN $=67096119 \&$ Site $=$ EhostLive.

Brigham, Eugene F And Joel F.Houston, 2006. Dasar-Dasar Manajemen Keuangan, Alih Bahasa Ali Akbar Yulianto, Buku Satu, Edisi Sepuluh, PT. Salemba Empat, Jakarta.

Djakman, Dkk (2008). Pengaruh Struktur Kepemilikan terhadap Luas Pengungkapan Tanggung Jawab Sosial (CSR Disclosure) pada Laporan Tahunan Perusahaan; Studi Empiris pada Perusahaan Publik yang Tercatat di Bursa Efek Indonesia Tahun 2006, Proceeding Simposium Nasional Akuntansi XI, Pontianak, 22-25 Juli 2008

Dwi Prastowo, Rifka Juliaty. 2002. Analisis Laporan Keuangan Konsep Dan Aplikasi. Yogyakarta : Unit Penerbit \& Percetakan AMP YKPN

ESENSI Volume 15 No.2 / Agustus 2012 Albertus Karjono dan Amelia Falah:"Pengaruh Perputaran Kas..."28pengaruh Perputaran Kas dan Perputaran Piutang Terhadap Rentabilitas Ekonomi pada Kpridi Lingkungan Bkn Albertus Karjonoamelia Falah Fakrinainstitut Bisnis Nusantar Jl. D.I. Panjaitan Kav 24 Jakarta 13340
Fraser, Lyn M Dan Ormiston, Ailen. 2004. Memahami Laporan Keuangan Edisi Keenam. Edisi Bahasa Indonesia. Terjemahan oleh Sam Setyautama. Jakarta : Indeks

Giulio Botazzi, Angelo Secchi, Dan Federico Tamagni, 2008. Productivity, Profitability, and Financial Performance. Journal of Industrial and Corporate Change; Vol 17; Number 4; Pp. 711-751. (Online), (Http://Proquest.Umi.Com/Pqdweb?Did $=1522630921 \&$ Fmt $=6 \&$ Clientid $=74186$ $\& R Q T=309 \&$ Vname $=$ Pqd $)$.

Harahap, Sofyan Syafri, (2008). Analisis Kritis atas Laporan Keuangan.Jakarta: PT Raja Grafindo Persada

Ikatan Akuntansi Indonesia. 2007 Pernyataan Standar Akuntansi Keuangan. Jakarta: Salemba Empat. , 2004. Pernyataan Standar Akuntansi Keuangan. Jakarta: Salemba Empat

Jumingan. 2011. Analisa Laporan Keuangan, Cetakan Keempat. Bandung:Bumi Aksara.

Jusuf Jopie. 2008. Analisis Kredit. Penerbit ANDI. Yogyakarta

Kakuru, J. 2005. Finance Decisions and The Business. 3rd Ed. Kampala International Publishers.

Kasmir, (2008). Bank dan Lembaga Keuangan Lainnya. Jakarta: Rajagrafindo Persada „. 2013. “Analisis Laporan Keuangan”. Edisi 1. Cetakan Ke-6. Jakarta: Rajawali Pers. 
Kew, J. And Watson, A. (2012).Financial Accounting: An Introduction. 4th Ed. Cape Town: Oxford Universuty Press.

Kieso,Dkk 2008Akuntansi Intermediate Edisi Keduabelas Jilid 2.Terjemahan Emil Salim. Jakarta Penerbit: Airlangga.

Keown, Arthur J. Et A1, 2005, Financial Management : Principles and Aplications 10th Edition, New Jersey, Pearson Prentice Hall

Libby,Robert,Libby, Patricia A\& Short Daniel G. (2008). Akuntansi Keuangan. Diterjemahkan J. Agung Seputro. Yogyakarta:Penerbit Andi.

Malik, M., Waseem, J. U., And Kifayat, U. 2011. Working Capital Management and Profitability Analysis of Firms of Textile Industry of Pakistan. Journal of Managerial Sciences, 6(2):155-165.

Moore, J., William, P. And Longernecker, J. (2010). Managing Small Business: An Entrepreneural Emphasis. 15th Ed. Australia: South-Western/Cengage Learning.

Munawir, S, 2002. Analisis Laporan Keuangan, Edisi Kedua, YPKN, Yogyakarta. , 2010. Analisis Laporan Keuangan. Edisi 4. Yogyakarta: Liberty

Mulyadi. 2001. Sistem Akuntansi. Jakarta: Salemba Empat.

M. Hanafi, Dkk. 2009. Analisis Laporan Keuangan. Edisi 4. UPP STIM YKPN. Yogyakarta.
Riyanto, Bambang. 2011. Dasar-Dasar Pembelanjaan Perusahaan. BPFE. Yogyakarta.

Romney, Marshall. B Dan Paul John Steinbart. 2008. Accounting Informasi System. Edisi Sembilan Buku Satu. Jakarta:Salemba Empat.

Sartono Agus, 2001. Manajemen Keuangan Teori dan Aplikasi. Yogyakarta: BPEFYogyakarta.

Syamsuddin, Lukman. (2009). Manajemen Keuangan Perusahaan (Konsep Aplikasi Dalam: Perencanaan, Pengawasan dan Pengambilan Keputusan). Jakarta: Rajawali Pers.

Sugiyono. (2013). Metode Penelitian Pendidikan (Pendekatan Kuantitatif, Kualitatif dan R\&D. Bandung: Alfabeta.

Syafri Harahap, Sofyan, 2008. Analisa Kritis atas Laporan Keuangan, PT. Raja Grafindo Persada, Jakarta.

Sinungan Muchdyansyah, 2000. Manajemen Dana Bank, Edisi Kedua. Jakarta : Bumi Aksara.

Subramanyam K.R Dan John J. Wild. 2010. Analisis Laporan Keuangan. Buku 2, Edisi 10. Jakarta: Salemba Empat.

Skousen, K. Fred, Earl K Stice, James D. Stice, 2004, Akuntansi Keuangan Menengah, Buku Satu, Salemba Empat, Jakarta.

Soemarso S. R. 2004. "Akuntansi Suatu Pengantar”. Buku Satu. Edisi Lima. Jakata: Salemba Empat

Sutrisno. 2013. Manajemen Keuangan. Edisi Pertama. Yogyakarta: EKONESIA. 
Van Horne, James C., Dan John M. Wachowics JR, (2005), Fundamentals of. Financial Management, Jakarta: Salemba Empat.

Warren, Fees Dan Reeve. 2008. Pengantar Akuntansi. Edisi Kedua Puluh Satu.Jakarta:Penerbit Salemba Empat

Willkinson Dan Cerullo, 2000, Accounting Information System Essential Concept and Application, Fourth Edition, New York, Jhon Wiley And Sons.

Wild, John J., K. R. Subramanyam, dan Robert E. Haley, Alih Bahasa: Yanivi S.Bachtiar, SE, Ak., S. Nurwahyu Harahap, SE, Ak. MBA., 2005. Statement Analysis (Analisis Laporan Keuangan Financial), Edisi Kedelapan, Buku Kedua Jakarta: Salemba Empat

Soemarso S. R. 2004. "Akuntansi Suatu Pengantar". Buku Satu. Edisi Lima. Jakata: Salemba Empat

Walsh, Ciaran. 2004. Key Management Ratios: Rasio-Rasio Manajemen Penting. Edisi Ketiga. Jakarta: Erlangga.

Syamsuddin, Lukman. 2000. Manajemen Keuangan Perusahaan. Edisi Baru, Cetakan Kelima. Jakarta: PT Rajagrafindo Persada

Weston J. Fred, Dkk. (1995). Manajemen Keuangan. Jakarta: BinarupaCrossan, M. M., \& Apaydin, M. (2010). A multidimensional framework of organizational innovation: A systematic 